\title{
Toward more resilient flood risk governance
}

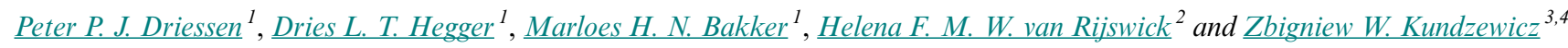

\begin{abstract}
Countries all over the world face increasing flood risks because of urbanization and the effects of climate change. In Europe, flooding is the most common of all natural disasters and accounts for the largest number of casualties and highest amount of economic damage. The current scientific debate on how urban agglomerations can be made more resilient to these flood risks includes a discussion on how a diversification, coordination, and alignment of flood risk management strategies (FRMSs), including flood risk prevention through proactive spatial planning, flood defense, flood risk mitigation, flood preparation, and flood recovery, can contribute to flood resilience. Although effective implementation of FRMSs can be considered a necessary precondition for resilience, efficient and legitimate flood risk governance can enhance this societal resilience to flooding. Governance and legal research has the potential to provide crucial insights into the debate on how to improve resilience. Yet the social sciences have only looked into this issue in a fragmented manner, often without a comparative scope. This special feature addresses this knowledge gap by focusing on the scope and workings of FRMSs, but also on cross-cutting topics such as uncertainties, distributional effects, solidarity, knowledge management, and citizen participation. The papers included in this feature are written by both policy analysts and legal scholars. The above-mentioned issues are thus approached via a multidisciplinary perspective. All papers convincingly show that one-size-fits-all solutions for appropriate and resilient flood risk governance arrangements do not exist. Governance arrangements should be tailored to the existing physical, socio-cultural, and institutional context. This requires an open and transparent debate between scientists and practitioners on the normative starting point of flood risk governance, a clear division of responsibilities, the establishment of connectivity between actors, levels, and sectors through bridging mechanisms, and adequate knowledge infrastructures, both nationally and internationally.
\end{abstract}

Key Words: climate change; Europe; flood risk governance; flood risk management strategies; resilience

\section{INTRODUCTION}

Flood risks are increasing throughout the world because of population growth, urbanization, and the effects of climate change (Bates et al. 2008, Steinführer et al. 2009, IPCC 2012, Kundzewicz 2012, Guha-Sapir et al. 2013, UN 2014, Ward et al. 2015, Arnell and Gosling 2016, Kundzewicz et al. 2016), which is why there is an ongoing search for better ways of protecting urbanized areas and the environment through improved flood risk management. Current and projected levels of flood impacts (see, for instance, Alfieri et al. 2015) give urgency to the challenge and importance of improving the flood resilience of societies. In literature and in practice, it is increasingly argued that a diversification, coordination, and alignment of flood risk management strategies (FRMSs), including prevention, defense, mitigation, preparation, and recovery, will make urban agglomerations more resilient to flood risks (Aerts et al. 2008, Wardekker et al. 2010, Innocenti and Albrito 2011, van den Brink et al. 2011, Hegger et al. 2014, Wesselink et al. 2015).

For a long time, natural and technical science perspectives have dominated the research on flood risk management. There is an abundance of commonly held natural science and technical knowledge on FRMSs. Despite all the uncertainty, there is no doubt that significant progress has been made on issues of technical measures, risk assessments, and future scenarios. However, flood risk management is not only a technical issue of building flood defenses and developing flood warning systems. It is also a matter of societal transformations and successful governance approaches. Although it is known that social and institutional factors often create strong barriers to the successful implementation of FRMSs (see also van den Brink et al. 2011,
OECD 2015), social-scientific research on flood risk management is still rare and a clear understanding of the governance challenges is lacking (Dieperink et al. 2016).

We hold that a governance perspective on flood risk management will give added value to the natural and technical science perspectives and could enhance our understanding of how societies can successfully cope with current and future flood risks. From a social science point of view, flood risk management in our opinion principally involves activating governmental and nongovernmental actors, stimulating fruitful cooperation between these actors, putting the right legal, economic, and communicative instruments in place, securing enforcement, enhancing connectivity between relevant policy sectors and between administrative levels, stimulating risk awareness among societal groups, and provoking societal debates on future perspectives and associated transformative pathways (Hegger et al. 2016a). To improve flood resilience in the face of urbanization and climate change, a governance perspective has complementary insights to offer. It tests the governing actors' abilities to collaborate, tests the presence and efficacy of policy strategies and instruments, provides understanding of the mechanisms through which strategies, actors, levels, and sectors can be bridged, and may inspire changes in societal debates and institutional settings (Hegger et al. 2016a). Change may require specific resources (finance, knowledge), new rules and regulations, and a transformation of policy cultures to ensure a clear division of responsibilities and the presence of a legal framework that enables the implementation and enforcement of newly developed flood risk policies and approaches. All this has to be achieved in adherence to the normative values and principles held in societies,

${ }^{1}$ Environmental Governance, Copernicus Institute of Sustainable Development, Utrecht University, The Netherlands, ${ }^{2}$ Utrecht Centre for Water, Oceans and Sustainability Law, Utrecht University School of Law, The Netherlands, ${ }^{3}$ Institute for Agricultural and Forest Environment, Polish Academy of Sciences, Poznan, Poland, ${ }^{4}$ Potsdam Institute for Climate Impact Research, Potzdam, Germany 
which should include effectiveness, legitimacy, social equity, transparency, accountability, and efficiency (Alexander et al. 2016).

\section{AIM AND SCOPE OF THE SPECIAL FEATURE}

This special feature aims to address the above-mentioned issues (see also the key concepts used in this special feature presented in Fig. 1) and focuses on flood risk governance practices and insights in a selection of European countries: England, Belgium, France, Germany, The Netherlands, Poland, and Sweden. European countries face increasing flood risks because of urbanization, with associated population and economic growth, and the effects of climate change, with the observed and expected increase of the frequency and intensity of heavy precipitation (Barredo 2007, Steinführer et al. 2009, Kundzewicz 2012, Guha-Sapir et al. 2013, Kundzewicz et al. 2013, Hegger et al. 2014). Multilayered FRMSs are advocated that take into account the probability of flooding as well as its potential consequences, i.e., exposure and vulnerability (Klijn et al. 2008). A prominent policy initiative is the EU Floods Directive (FD, Directive 2007/60/EC), which stresses the importance of FRMSs such as prevention, mitigation, and preparedness. The Floods Directive allows member states a large range of policy discretion to choose those FRMSs that best suit their country. This approach respects the differences in member states and will lead to the development of different approaches in Europe. In addition, various countries have also started to take into account response and recovery strategies (Kellens et al. 2013, Dieperink et al. 2016). As stated before, an assumption in many recent scientific and policy debates is that urban agglomerations vulnerable to flooding will be more resilient if multiple FRMSs are applied simultaneously and are aligned (Aerts et al. 2008, Wardekker et al. 2010, van den Brink et al. 2011, Hegger et al. 2014).

Fig. 1. Tag cloud based on the 15 titles and abstracts in this special feature (the figure gives more prominence to words that appear more often in the abstracts).

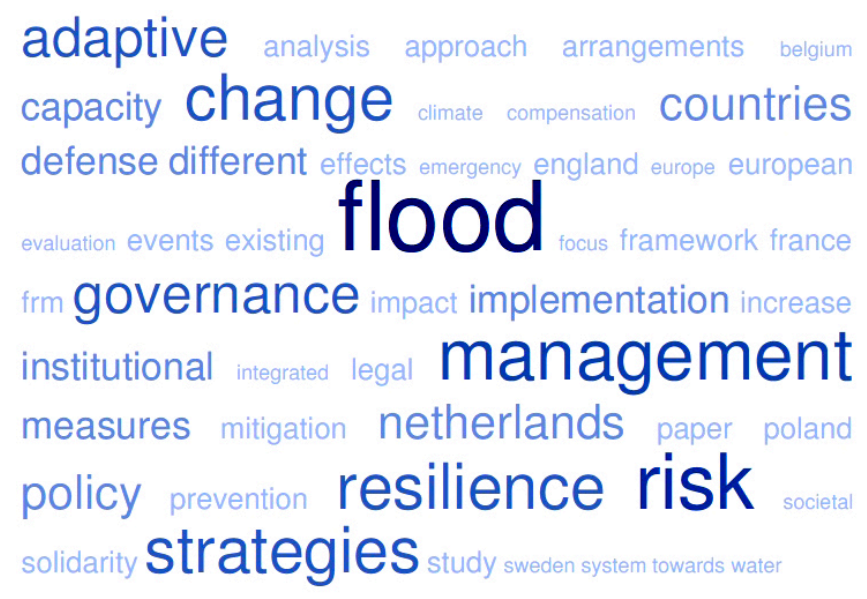

This special feature aims to contribute to insights into which governance arrangements may facilitate the implementation of a diversified, resilient set of FRMSs. Governance arrangements can be defined as "the institutional constellations resulting from an interplay between the actors and actor coalitions involved in all policy domains relevant for flood risk management; their dominant discourses; formal and informal rules of the game; and the power and resource base of the actors involved" (Hegger et al. 2013:5, 2014:4131). Associated topics that will be addressed in this special feature are the role of the EU Floods Directive in the implementation of a diversified set of FRMSs; coping with complexity and uncertainties; distributional effects of flood risk management strategies; the role of the solidarity principle in flood risk governance; new knowledge requirements resulting from implementing a diversified set of strategies; and citizens' involvement in flood risk management.

Through its focus on "more resilient flood risk governance," the special feature engages with two prominent academic debates that fit the aim and scope of Ecology and Society. First, this special feature contributes to the debates on (governance of) the resilience of social-ecological systems that is being advanced in the journal (e.g., Walker et al. 2004, Lebel et al. 2006, Folke et al. 2010). With the special feature we intend to contribute to this literature by operationalizing the concept of resilience and applying it in a detailed way to the empirical field of flood risk governance. Second, the special feature contributes to the literature on flood risk governance by providing a combined social scientific and legal analysis, taking into account various flood risk management strategies. Both contributions can be made because the analyses in the included papers are embedded in the relevant bodies of literature and draw on a large empirical basis.

\section{FLOOD RISK MANAGEMENT STRATEGIES}

Because the main focus of this special feature lies on the diversification of FRMSs, we will briefly touch upon the concepts of both diversification and strategies. When considering FRMSs, there is a range of categorizations evident in the current literature. The vast literature on the need to manage the resilience of socialecological systems has paid much attention to flood risk management (FRM) and its strategies (Aerts et al. 2008, Klijn et al. 2008, Wardekker et al. 2010, Kellens et al. 2013). Five basic types of strategies can be identified (Fig. 2): flood risk prevention (through proactive spatial planning), flood defense, flood risk mitigation, flood preparation, and flood recovery (Hegger et al. 2014). In literature and in practice, it is increasingly argued that a diversification, coordination, and alignment of these FRMSs will make urban agglomerations more resilient to flood risks, e.g., by focusing on both probability and consequence-reducing approaches, by tailoring these approaches to the magnitude of the risk and to the types of flooding, e.g., pluvial, fluvial, coastal, or flash floods (Aerts et al. 2008, Wardekker et al. 2010, Innocenti and Albrito 2011, van den Brink et al. 2011, Hegger et al. 2014, Mees et al. 2014). Diversification would lead to more redundancy and choice options, flexibility, and adaptability of flood risk management.

In this special feature we will cluster the five strategies by the three main occasions, before a flood, during a flood, and after a flood:

\section{Before a flood event}

- Flood risk prevention aims to decrease the consequences of flooding by decreasing the exposure of people and property via measures that prohibit or discourage development in areas at risk of flooding, e.g., spatial planning, reallotment 
Fig. 2. Five types of flood risk management strategies (adopted from Hegger et al. 2014 with visualizations taken from Raadgever et al. 2016 and reprinted with permission).

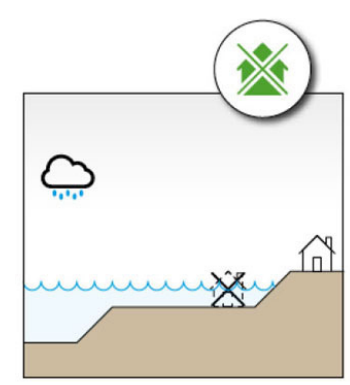

Flood Risk Prevention

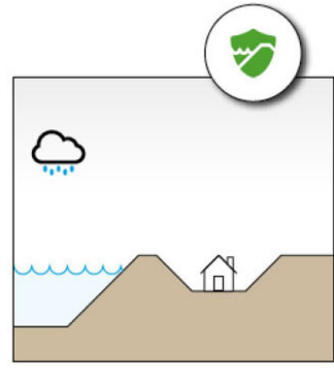

Flood Defence

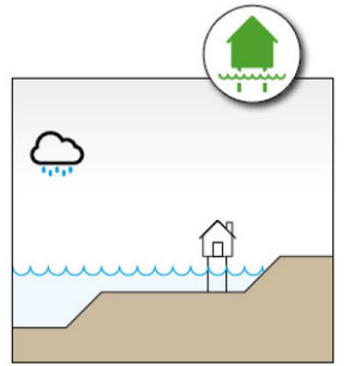

Flood Risk Mitigation

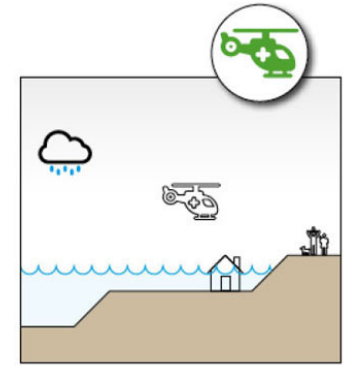

Flood Preparation and Respons

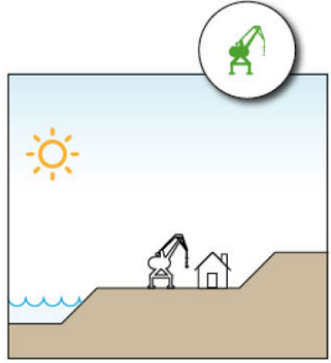

Flood Recovery policy, expropriation policy. The main focus of this strategy is "keeping people away from water" by building only outside flood-prone areas.

- Flood defense measures aim to decrease the probability of flooding. This is accomplished using infrastructural flood defenses, such as dikes and weirs; by increasing the capacity of existing channels; by increasing space for water and by creating space for upstream water retention. In other words, "keeping water away from people."

- Flood risk mitigation focuses on decreasing the magnitude or consequences of flooding through measures inside the vulnerable area. The magnitude of flooding can be decreased by retaining or storing water in or under the floodprone area, e.g., rain water retention. The consequences can be reduced by flood zoning or (regulations for) flood-proof building.

\section{During a flood event}

- Flood preparation and response measures include developing flood warning systems, preparing disaster management and evacuation plans, and managing a flood when it occurs.

\section{After a flood event}

- Flood recovery includes reconstruction and rebuilding plans as well as public compensation or private insurance systems.

\section{COUNTRIES}

The articles included in this special feature focus on seven European countries, or comparisons of several of these: Belgium, England, France, Germany, the Netherlands, Poland, and Sweden. These countries are all part of the European Union and as such implement the EU Floods Directive (FD, 2007/60EC). However, they differ tremendously from one another in terms of physical conditions, actual flood experience, their departure point in terms of the FRMSs and flood risk governance arrangements that are in place, and their administrative and legal context, amongst other things (Hegger et al. 2016a). The countries are furthermore diverse in terms of the general direction of attempts to expand the application of FRMSs, and the significance of flooding in terms of casualties or economic losses, their dominant administrative structure and culture. By comparing such diverse countries, detailed insights into the potential links of FRMSs and the degree of flood resilience can be made.

Floods in countries included in this special feature are caused by various mechanisms. Since 1950, pluvial and fluvial floods have occurred in all seven countries (Belgium, England, France, Germany, The Netherlands, Poland, Sweden). Flash floods have occurred in England, France, Germany, and Poland, while snowmelt floods have happened in Sweden, Poland, and Germany. Coastal floods have occurred in the Netherlands, England, Belgium, Germany, and Poland. There have been many floods in the seven countries studied between 2002 and 2013, some of which were very destructive. The highest flood damage, on a pan-European scale, occurred in 2002, and included Germany and France. In both England and Germany, the total flood damage in 2002-2013 exceeded 20 billion Euro, while in Poland, the flood of 2010 alone caused damages in the order of $1 \%$ of GDP. The number of flood-related fatalities in 2002-2013 exceeds 150 in France, 50 in England, and 20 in each of Poland and Germany. In England, there have been multiple large floods since 2000, such as events in October 2000, summer 2007, and winters 2013/2014 and 2015/2016. There have been major floods in Central Europe in July 1997, spring and summer of 2010 (both floods damaged parts of Poland and Germany), and June 2013 (Germany; Barredo 2007, Kundzewicz 2012, Kundzewicz et al. 2013, Alfieri et al. 2015, Kundzewicz et al. 2016). The most recent large floods occurred in Germany, France, and Belgium in June 2016.

\section{OVERVIEW OF THE CONTENT OF THIS SPECIAL FEATURE}

The 15 papers composing this special feature can be grouped under four subthemes: (a) the EU Floods Directive, (b) FRMSs, (c) cross-cutting issues, and (d) resilient flood risk governance.

\section{EU Floods Directive}

The simultaneous implementation of several FRMSs is often considered to contribute to increasing societal resilience to flooding. The European Floods Directive (2007/60/EC; FD) has stimulated the implementation of a diversified set of FRMSs in European countries. The FD provides procedural rules with which EU member states have to comply such as the designation of areas 
of potential significant flood risk (first completed in 2011), the production of flood hazard and flood risk maps (first completed in 2013), and the production of flood risk management plans (FRMPs, first completed in 2015). The paper by Priest et al. (2016) provides an analysis of the implementation of this Directive in six European countries. The authors conclude, amongst other things, that the FD has induced a diversification in all six investigated countries, but to a different extent. On opposite sides of the spectrum is Poland on the one hand, in which the Directive has had a stronger impact in the creation of legal instruments for FRM and has led to a diversification of strategies, and England and the Netherlands on the other hand, where the impact has been minimal because of a solid package of pre-existing FRM legal instruments and measures and a goodness-of-fit with the requirements of the FD. In Sweden, Belgium, and France it has stimulated greater interest and induced further diversification. The authors recommend focusing the FD more on transboundary river management by requiring more stringent cooperation between competent authorities in International River Basin Districts. Furthermore, they recommend more substantial provisions that can make the FD more enforceable and effective. After all, the protection of citizens against floods and a decrease of casualties and damage is ultimately the main raison d'être of this Directive.

\section{Flood risk management strategies}

In the paper by Gralepois et al. (2016) the flood defense strategies in six European countries (Belgium, England, France, the Netherlands, Poland, and Sweden) are analyzed. Although they do not find radical changes in either of the countries, they do find that the defense strategy in all countries has created more room for local, private, and individual responsibilities. In all countries except Sweden, defense remains the primary method of protection, leading the authors to conclude that flood defense has remained a cornerstone of European flood risk management.

The paper by Kaufmann et al. (2016) describes the way discourses around floods are framed in the Netherlands and Poland through media outlets, and what this tells us about corresponding policy change in the future. Their analysis, based on a conceptual framework linking events to both an (agency-focused) framing perspective and a more (structure-based) institutional perspective, shows, among other things, that floods have different societal impacts, that they can increase the actors' receptiveness for different frames, possibly leading to different institutional effects, and can facilitate a shift toward different forms of resilience.

The paper by Gilissen et al. $2016 a$ is a cross-country comparative study on flood emergency management strategies. The authors apply a comprehensive evaluation framework to discover whether anything can be said about the conditions for the success of socalled effective emergency management in England, France, the Netherlands, Poland, and Sweden. Although they find similar strengths and weaknesses in these strategies, they also find surprising differences. The authors describe a number of potentially shared constraints to increasing the effectiveness of emergency management strategies.

Thieken et al. (2016) studied the German flood risk management system to see what changes have been made since the destructive flood of 2002. The authors propose an enhanced flood risk management cycle, identify four levels in the German system that need improvements, while at the same time pointing to areas such as transboundary and cross-sectoral cooperation that still need further investigation.

Fournier et al. (2016) dive into the issue of the governance of flood risk mitigation in six European countries (Belgium, England, France, the Netherlands, Poland, and Sweden) to see if mitigation can be considered as adaptive governance, and if so, to what extent. The authors use five criteria to look at mitigation from an adaptive point of view. They conclude that the flood mitigation strategy provides various opportunities for actors to further pursue forms of adaptive governance. However, the extent to which the mitigation strategy is capable of doing so varies across countries, and its role in stimulating adaptive governance was found to be strongest in Belgium and England.

\section{Cross-cutting issues}

In practice, flood risk managers are confronted with important challenges when implementing a combination of flood risk management strategies. For instance, how do they cope with complexity and uncertainties, distributional effects, the solidarity principle, new requirements of knowledge management, and the participation of citizens in decision-making procedures? These issues are discussed in separate papers in this special feature.

Goytia et al. (2016) analyze the extent to which regulatory frameworks for flood defense infrastructure in a selection of European countries allow for actors to handle change and uncertainty associated with flood risks, while simultaneously upholding legal principles such as the rule of law. The authors conclude that legal rules are most open to complexity and uncertainty when infrastructures do not yet exist. After the infrastructure is built, the focus on legal rules turns to the safety of the structure and existing property rights, and it becomes increasingly difficult to balance this with other desirable outcomes.

Measures carried out for strategies such as flood prevention and flood defense to avoid damage caused by floods can cause harm such as the devaluation of property or loss of income. The paper by van Doorn-Hoekveld et al. (2016) discusses this issue and analyzes the extent to which several European countries cope with these distributional effects. This issue has hardly been discussed in literature so far, in contrast to the attention paid to the compensation for harm after a flood has occurred. The paper provides an overview of different compensation regimes, followed by an explanation of differences, focusing on factors such as property rights and legal principles underlying the regimes. The paper concludes that the legitimacy of preflood measures will be increased when based on an elaborated and fair compensation regime that includes all interests.

Compensation is also a key topic of the paper by Suykens et al. (2016). This paper provides a comparative legal analysis of the financial compensation mechanisms following floods, be it through insurance, public funds, or a combination of both. The comparative analysis in four European countries (Belgium, France, The Netherlands, and England) focuses especially on the link between the recovery strategy on the one hand and prevention and mitigation strategies on the other. According to the authors there seems to be great potential within the recovery strategy for 
promoting preventive action, for example, in terms of discouraging citizens from living in high-risk areas, or encouraging the uptake of mitigation measures such as adaptive building. However, this large potential is yet to be realized, in part because of insufficient consideration and promotion of these connections within existing legal frameworks.

Solidarity is another principle that can play a key role in the legitimacy of flood risk management measures. Flood risk measures are mostly taken for the common interest and can be interpreted as an act of solidarity, i.e., that there is no equivalence between what one contributes and what one gets in return. And as the strongest shoulders bear the heaviest duties, it reduces the gap between the fortunate and the unfortunate. However, solidarity in flood risk governance is also often contested, when there is no agreement about the fairness of the contributions and returns. The paper by Keessen et al. (2016) investigates the role the solidarity principle plays in strategies for adaptation in a broad range of issues in the nexus of climate adaptation and water governance in the Netherlands. The authors conclude that the solidarity principle has quite a firm position in Dutch water management despite some controversies. The paper contributes to the debate on water governance and climate adaptation by presenting different forms of solidarity and by emphasizing the normative underpinnings of this principle. According to the authors, these normative issues need to be broadly discussed in society to enhance the legitimacy of policies that are fully or partly based on the solidarity principle.

The paper by Bergsma (2016) investigates the role of knowledge in the transition toward a more integrated (and diversified) flood risk management. A basic assumption in this paper is that this transition requires "new" knowledge. For instance, in the Netherlands the knowledge structure was for a long time mainly based on engineering expertise because of the emphasis on flood defenses. With the development of more integrated management approaches new knowledge requirements also emerged, but these were insufficiently recognized. The paper highlights the importance of incorporating multiple sources of knowledge to support the diversification of risk management strategies, which also means including other experts in the policy processes.

Across Europe, citizens are increasingly expected to participate in the implementation of flood risk management strategies, by engaging in activities to enhance preparedness and implementing property-level measures. In the paper by Mees et al. (2016) this is labeled as "coproduction." The paper focuses on the extent to which coproduction is evident in five European countries. Coproduction seems to be most prominent in discourse and practice in England and is emergent in France and Flanders (Belgium). By contrast, in the Netherlands and Poland it remains almost exclusively reliant on governmental protection measures and is thereby consultation based. Analysis revealed how these actions are motivated by different underlying rationales, which in turn shape the type of approaches and the degree of institutionalization of coproduction.

\section{Resilient flood risk management}

The paper by Gersonius et al. (2016) addresses the debate as to how transformations from resistance-based to resilience-based approaches can be achieved by studying the implementation of various measures that aim to enhance the flood resilience of the
Dutch "Island of Dordrecht." The case illustrates that a multilayered, i.e., diversified, approach is more effective and efficient than its resistant, i.e., flood defense dominated, counterpart and provides substantial cobenefits, but that it is incompatible with the existing institutional framework, a challenge that will also be present in other countries with an established institutional framework for resistance-based approaches. The authors recommend searching for ways to reinterpret existing frameworks and applying them differently by setting up pilots and experiments to foster social learning.

Van Buuren et al. (2016) analyze the absence of wider institutional change toward resilience-based (as opposed to resistance-based) approaches in The Netherlands, despite the fact that the so-called multilayered safety approach was formally included in the Dutch Delta Program in 2009, and despite forceful triggers such as climate change and economic developments. The authors conclude that mechanisms of path dependency such as the existing power asymmetries between competing coalitions and the intricate complexity of flood policies are even stronger in The Netherlands than in other countries because of the country's reliance on and the relative success of the flood defense strategy. Nevertheless, the authors have identified a gradual change process in which ideas about resilience are slowly gaining more impact.

The paper by Hegger et al. (2016b) assesses the now prominent assumption that a diversification of flood risk management strategies leads to resilience. They propose that to assess flood management portfolios, the resilience concept should be operationalized into three capacities: capacity to resist, capacity to absorb and recover, and capacity to adapt and transform, and compare six countries' achievements in terms of these capacities. The authors have found that having a diverse portfolio of strategies in place contributes to resilience, especially in terms of the capacity to absorb/recover and the capacity to adapt and transform. However, the authors also nuance this thesis in that they see different ways to be resilient. They furthermore highlight the importance of explicating the normative starting points of flood risk governance in a country, taking into account the unavoidable trade-offs between the three capacities and assessing strategies' fit with existing physical circumstances and institutional frameworks.

\section{OUTLOOK, CONCLUSIONS, AND RECOMMENDATIONS}

As the papers in this special feature convincingly show, there are no one-size-fits-all solutions for the reduction of flood risks. Besides physical and geographical factors, historical flood risk management, societal and cultural norms, administrative and legal frameworks are all important factors that influence flood risk management and governance (Fournier et al. 2016, Gersonius et al. 2016, Gilissen et al. 2016a, Gralepois et al. 2016, Hegger et al. 2016b, Kaufmann et al. 2016, Suykens et al. 2016, Thieken et al. 2016, van Buuren et al. 2016, van Doorn-Hoekveld et al. 2016). Contextual, historical, and contemporary flood risk debates all have implications for how policies and legal frameworks should be shaped (Hegger et al. 2016a). Nevertheless, these papers provide some interesting, novel, and general insights and lessons on flood risk management and flood risk governance.

1. Although the authors of papers in this special feature endorse approaches aimed at diversification of FRMSs 
based on the conducted research (Bergsma 2016, Hegger et al. 2016b, van Buuren et al. 2016), these approaches should fit within the existing national and local context. Countries differ in their approaches to diversification. In the Netherlands, Poland, France, and Belgium for instance, we see a desire to create a back-up layer of contingency. England has been diversified for 65 years, while Sweden is currently diversifying because of climate change concerns. These existing approaches form the starting point and need to be taken into account to provide the contextual understanding necessary for governance changes to be implemented (Hegger et al. 2016b).

2. Steering at different levels of government (EU, national, regional/local, and transboundary) is necessary, but the division of tasks and responsibilities should be further clarified. In addition, the role of citizens, NGOs, and businesses should be considered (Hegger et al. 2016b, Mees et al. 2016, Suykens et al. 2016). Increased experimentation with public-private partnerships is needed to assess the ability and effectiveness of these partnerships and to develop new knowledge that may gradually change existing policy discourses and thereby instigate wider institutional change (Bergsma 2016, Gersonius et al. 2016, Mees et al. 2016, Suykens et al. 2016, van Buuren et al. 2016).

3. There is a need to develop connectivity between different flood risk management strategies, between governmental levels, and between flood-relevant policy domains such as spatial planning and crisis management (Gilissen et al. 2016a, Suykens et al. 2016). A better coordinated and complementary (rather than undermining) suite of strategies will ensure effective flood risk management. This requires different types of bridging mechanisms (Hegger et al. 2016a, Gilissen et al. 2016b), such as coordinating actors; procedural duties and instruments; formal rules and regulations; financial and knowledge resources and bridging concepts (Bergsma 2016, Suykens et al. 2016).

4. Linked to the last point, diversification of flood risk management strategies needs to be accompanied by suitable investments in the development of these strategies (Fournier et al. 2016, Gilissen et al. 2016a, Gralepois et al. 2016, Kaufmann et al. 2016, Thieken et al. 2016). Financial investments and other resources channeled into one strategy should not lead to underinvestment in other strategies. Diversification also implies investments in legal frameworks, for instance, building regulations in the field of spatial planning or emergency management frameworks (Gilissen et al. 2016a).

5. Legitimacy is a well-established principle of good governance and seen as essential for effective governance in democratic societies (Alexander et al. 2016). This requires the enhancement of public participation in policy development, policy implementation (Mees et al. 2016) and increased flood awareness of citizens. Regarding policies and legislation, greater attention needs to be focused on how effective participation, rather than consultation, can be delivered.
6. Flood risk governance arrangements require long-term planning (visioning) to underscore adaptive approaches and to enable the sustainable use of resources (Bergsma 2016, Gersonius et al. 2016, van Buuren et al. 2016). The shortterm measures should be delivered as part of this longer term perspective on flood risk management. Proactive, rather than reactive responses to flooding are required. To achieve such approaches, learning and experimentation is pivotal (van Buuren et al. 2016). At the same time, shock events will open up institutional arrangements and provide room for innovations, provided that actors manage to seize these opportunities, for instance, by carefully selecting the discursive frames they introduce (Kaufmann et al. 2016).

7. The Floods Directive has a greater role to play in stimulating the development of appropriate flood risk governance arrangements that increase societal resilience to floods (Priest et al. 2016). For instance, for the next implementation round of the FD, a substantive requirement regarding the content of flood risk management plans should be added to explicitly address the issue of the responsibilities of actors. Bridging mechanisms could also to some extent be included in the FD, for instance, making it the duty of property sellers to inform potential buyers of flood risks (as is currently the case in the Flemish region of Belgium). Second, it would be worthwhile to critically re-evaluate the content of the FD for its enforceability by citizens, and to make clear what they can ask for in the courts. Finally, the FD should further stimulate transboundary flood risk governance.

In summary, we conclude that there are no one-size-fits-all solutions and that in practice one should search for appropriate governance arrangements that fit into the national and regional context. However, from the papers included in this special feature and the underlying bodies of literature, it becomes clear that to enhance flood resilience a wider range of modes of governance should be applied than the currently dominant centralized and decentralized governance modes with their primary focus on public actors (see also Driessen et al. 2012). Progress toward flood resilience calls for collaborative and deliberative modes of governance in addition to these traditional modes. Developing "smart" mixes of governance modes is seen as necessary to deal with the complex, multiscale, cross-sectoral, and long-term dimensions of flood risks. In other words, the variety of strategies that could and should be applied to decrease flood risks calls for a flexible repertoire of governance modes. European countries should learn from each other in this respect, for instance where different modes succeed or fail or how modes complement or hamper each other. The European Floods Directive could play a crucial role in stimulating such learning processes. The papers included in this special feature may also be inspiring for countries outside Europe because the underlying problems, mechanisms, and governance challenges will be similar.

Responses to this article can be read online at: http://www.ecologyandsociety.org/issues/responses. $\mathrm{php} / 8921$ 


\section{Acknowledgments:}

This paper has been written in the framework of the European Union's Seventh Programme for Research, Technological Development and Demonstration within the STAR-FLOOD project. This research has received funding from the European Commission under grant agreement no. 308364. We would also like to thank the many reviewers of papers included in this special feature. Their helpful comments and suggestions contributed tremendously to the quality of the papers.

\section{LITERATURE CITED}

Aerts, J. C. J. H., W. Botzen, A. Van der Veen, J. Krywkow, S. Werners. 2008. Dealing with uncertainty in flood management through diversification. Ecology and Society 13(1):41. [online] URL: http://www.ecologyandsociety.org/vol13/iss1/art41/

Alexander, M., S. Priest, and H. Mees. 2016. A framework for evaluating flood risk governance. Environmental Science \& Policy 64:38-47. http://dx.doi.org/10.1016/j.envsci.2016.06.004

Alfieri, L., L. Feyen, F. Dottori, and A. Bianchi. 2015. Ensemble flood risk assessment in Europe under high end climate scenarios. Global Environmental Change 35:199-212. http://dx.doi. org/10.1016/j.gloenvcha.2015.09.004

Arnell, N. W., and S. N. Gosling. 2016. The impacts of climate change on river flood risk at the global scale. Climatic Change 134 (3):387-401. http://dx.doi.org/10.1007/s10584-014-1084-5

Barredo, J. I. 2007. Major flood disasters in Europe: 1950-2005. Natural Hazards 42(1):125-148. http://dx.doi.org/10.1007/ s11069-006-9065-2

Bates, B.C., Z. W. Kundzewicz, S. Wu, and J. P. Palutikof, editors. 2008. Climate change and water. Technical Paper of the Intergovernmental Panel on Climate Change. IPCC Secretariat, Geneva, Switzerland.

Bergsma, E. 2016. Changed knowledge requirements for spatial flood governance. Ecology and Society 21(4):40. http://dx.doi. org/10.5751/ES-08952-210440

Dieperink, C., D. L. T. Hegger, M. H. N. Bakker, Z. W. Kundzewicz, C. Green, and P. P. J. Driessen. 2016. Recurrent governance challenges in the implementation and alignment of flood risk management strategies: a review. Water Resources Management 30(13):4467-4481. http://dx.doi.org/10.1007/ s11269-016-1491-7

Driessen, P. P. J., C. Dieperink, F. van Laerhoven, H. Runhaar, and W. J. V. Vermeulen. 2012. Towards a conceptual framework for the study of shifts in modes of environmental governance: experiences from the Netherlands. Environmental Policy and Governance 22(3):143-160. http://dx.doi.org/10.1002/eet.1580

Folke, C., S. R. Carpenter, B. Walker, M. Scheffer, T. Chapin, and J. Rockström. 2010. Resilience thinking: integrating resilience, adaptability and transformability. Ecology and Society 15(4):20. [online] URL: http://www.ecologyandsociety.org/vol15/iss4/ art20/

Fournier, M., C. Larrue, M. Alexander, D. Hegger, M. Bakker, M. Pettersson, A. Crabbé, H. Mees, and A. Chorynski. 2016.
Flood risk mitigation in Europe: how far away are we from the aspired forms of adaptive governance? Ecology and Society 21 (4):49. https://doi.org/10.5751/ES-08991-210449

Gersonius, B., A. van Buuren, M. Zethof, and E. Kelder. 2016. Resilient flood risk strategies: institutional preconditions for implementation. Ecology and Society 21(4):28. http://dx.doi. org/10.5751/ES-08752-210428

Gilissen, H. K., M. Alexander, J.-C. Beyers, P. Chmielewski, P. Matczak, T. Schellenberger, and C. Suykens. 2016b. Bridges over troubled waters: an interdisciplinary framework for evaluating the interconnectedness within fragmented domestic flood risk management systems. Journal of Water Law 25(1):12-26.

Gilissen, H. K., M. Alexander, P. Matczak, M. Pettersson, and S. Bruzzone. 2016a. A framework for evaluating the effectiveness of flood emergency management systems in Europe. Ecology and Society 21(4):27. http://dx.doi.org/10.5751/ES-08723-210427

Goytia, S., M. Pettersson, T. Schellenberger, W. J. van DoornHoekveld, and S. Priest. 2016. Dealing with change and uncertainty within the regulatory frameworks for flood defense infrastructure in selected European countries. Ecology and Society 21(4):23. http://dx.doi.org/10.5751/ES-08908-210423

Gralepois, M., C. Larrue, M. Wiering, A. Crabbé, S. Tapsell, H. Mees, K. Ek. and M. Szwed. 2016. Is flood defense changing in nature? Shifts in the flood defense strategy in six European countries. Ecology and Society 21(4):37. http://dx.doi. org/10.5751/ES-08907-210437

Guha-Sapir, D., P. Hoyois, and R. Below. 2013. Annual disaster statistical review 2012: The numbers and trends. Centre for Research on the Epidemiology of Disasters, Brussels, Belgium.

Hegger, D. L. T., P. P. J. Driessen, M. H. N. Bakker, editors. 2016. $A$ view on more resilient flood risk governance: key conclusions of the STAR-FLOOD project. STAR-FLOOD Consortium, Utrecht, the Netherlands. ISBN: 978-94-91933-13-4

Hegger, D. L. T., P. P. J. Driessen, C. Dieperink, M. Wiering, G. T. Raadgever, H. F. M. W. Van Rijswick. 2014. Assessing stability and dynamics in flood risk governance: an empirically illustrated research approach. Water Resources Management 28:4127-4142. http://dx.doi.org/10.1007/s11269-014-0732-X

Hegger, D. L. T., P. P. J. Driessen, M. Wiering, H. F. M. W. Van Rijswick, Z. W. Kundzewicz, P. Matczak, A. Crabbé, G. T. Raadgever, M. H. N. Bakker, S. J. Priest, C. Larrue, and K. Ek. 2016. Toward more flood resilience: Is a diversification of flood risk management strategies the way forward? Ecology and Society 21(4):52. https://doi.org/10.5751/ES-08854-210452

Hegger, D. L. T., C. Green, P. P. J. Driessen, M. H. N. Bakker, C. Dieperink, A. Crabbé, K. Deketelaere, B. Delvaux, C. Suykens, J.-C. Beyers, M. Fournier, C. Larrue, C. Manson, W. van DoornHoekveld, H. F. M. W. Van Rijswick, Z. W. Kundzewicz, and S. Goytia Casermeiro. 2013. Flood risk management in Europe: similarities and differences between the STAR-FLOOD consortium countries. STAR-FLOOD Consortium, Utrecht, The Netherlands.

Innocenti, D., and P. Albrito. 2011. Reducing the risks posed by natural hazards and climate change: the need for a participatory dialogue between the scientific community and policy makers. 
Environmental Science \& Policy 14(7):730-733. http://dx.doi. org/10.1016/j.envsci.2010.12.010

Intergovernmental Panel on Climate Change (IPCC). 2012. Managing the risks of extreme events and disasters to advance climate change adaptation. A special report of Working Groups I and II of the Intergovernmental Panel on Climate Change. C. B. Field, V. Barros, T. F. Stocker, D. Qin, D. J. Dokken, K. L. Ebi, M. D. Mastrandrea, K. J. Mach, G.-K. Plattner, S. K. Allen, M. Tignor, and P. M. Midgley, editors. Cambridge University Press, Cambridge, UK.

Kaufmann, M., J. Lewandowski, A. Choryński, and M. Wiering. 2016. Shock events and flood risk management: a media analysis of the institutional long-term effects of flood events in the Netherlands and Poland. Ecology and Society 21(4):51. https:// doi.org/10.5751/ES-08764-210451

Keessen, A., M. J. Vink, M. Wiering, D. Boezeman, W. Ernst, H. Mees, S. Van Broekhoven, and M. C. J. Van Eerd 2016. Solidarity in water management. Ecology and Society 21(4):35. http://dx. doi.org/10.5751/ES-08874-210435

Kellens, W., W. Vanneuville, E. Verfaillie, E. Meire, P. Deckers, and P. De Maeyer. 2013. Flood risk management in Flanders: past developments and future challenges. Water Resources Management 27:3585-3606. http://dx.doi.org/10.1007/s11269-013-0366-4

Klijn, F., P. Samuels, and A. Van Os. 2008. Towards flood risk management in the EU: state of affairs with examples from various European countries. International Journal of River Basin Management 6(4):307-321. http://dx.doi.org/10.1080/15715124.$\underline{2008.9635358}$

Kundzewicz, Z. W., editor. 2012. Changes in flood risk in Europe. IAHS, Wallingford, UK. http://dx.doi.org/10.1201/b12348

Kundzewicz, Z. W., V. Krysanova, R. Dankers, Y. Hirabayashi, S. Kanae, F. F. Hattermann, S. Huang, P. C. D. Milly, M. Stoffel, P. P. J. Driessen, P. Matczak, P. Quevauviller, H.-J. Schellnhuber. 2016. Differences in flood hazard projections in Europe - their causes and consequences for decision-making. Hydrological Science Journal. 1-14. http://dx.doi.org/10.1080/02626667.2016.1241398

Kundzewicz, Z. W., I. Pińskwar, and R. Brakenridge. 2013. Large floods in Europe, 1985-2009. Hydrological Science Journal 58 (1):1-7. http://dx.doi.org/10.1080/02626667.2012.745082

Lebel, L., J. M. Anderies, B. Campbell, C. Folke, S. HatfieldDodds, T. P. Hughes, and J. Wilson. 2006. Governance and the capacity to manage resilience in regional social-ecological systems. Ecology and Society 11(1):19. [online] URL: http://www. ecologyandsociety.org/vol11/iss1/art19/

Mees, H., A. Crabbé, M. Alexander, M. Kaufmann, S. Bruzzone, L. Lévy, and J. Lewandowski. 2016. Coproducing flood risk management through citizen involvement: insights from crosscountry comparison in Europe. Ecology and Society 21(3):7. http://dx.doi.org/10.5751/ES-08500-210307

Mees, H. L. P., J. Dijk, D. Van Soest, P. P. J. Driessen, M. H. F. M. W. Van Rijswick, and H. Runhaar. 2014. A method for the deliberate and deliberative selection of policy instrument mixes for climate change adaptation. Ecology and Society 19(2):58. http://dx.doi.org/10.5751/es-06639-190258
Organisation for Economic Co-operation and Development (OECD). 2015. OECD principles on water governance. OECD, Paris, France.

Priest, S. J., C. Suykens, H. F. M. W. Van Rijswick, T. Schellenberger, S. B. Goytia, Z. W. Kundzewicz, W. J. Van DoornHoekveld, J.-C. Beyers, and S. Homewood. 2016. The European Union approach to flood risk management and improving societal resilience: lessons from the implementation of the Floods Directive in six European countries. Ecology and Society 21 (04):50. https://doi.org/10.5751/ES-08913-210450

Raadgever, G. T., N. Booister, M. Steenstra, N. Van der Schuit, J. Van den Bossche, J. Jadut, F. Ohls, W. Kiewisz, and D. Lewis. 2016. Practitioner's guidebook - inspiration for flood risk management strategies and governance. STAR-FLOOD Consortium, Utrecht, The Netherlands.

Steinführer, A., C. Kuhlicke, B. De Marchi, A. Scolobig, S. Tapsell, and S. Tunstall. 2009. Local communities at risk from flooding. Social vulnerability, resilience and recommendations for flood risk management in Europe. Final report for FLOODsite. European Commission, Brussels, Belgium.

Suykens, C., S. J. Priest, W. J. van Doorn-Hoekveld, T. Thuillier, and M. van Rijswick. 2016. Dealing with flood damages: will prevention, mitigation, and ex post compensation provide for a resilient triangle? Ecology and Society 21(4):1. http://dx.doi. org/10.5751/ES-08592-210401

Thieken, A. H., S. Kienzler, H. Kreibich, C. Kuhlicke, M. Kunz, B. Mühr, M. Müller, A. Otto, T. Petrow, S. Pisi, and K. Schröter. 2016. Review of the flood risk management system in Germany after the major flood in 2013. Ecology and Society 21(2):51. http:// dx.doi.org/10.5751/ES-08547-210251

United Nations, Department of Economic and Social Affairs, Population Division. 2014. World urbanization prospects: the 2014 revision. Highlights (ST/ESA/SER.A/352). United Nations, Department of Economic and Social Affairs, Population Division, New York, New York, USA.

Van Buuren, A., G. J. Ellen and J. F. Warner. 2016. Pathdependency and policy learning in the Dutch delta: toward more resilient flood risk management in the Netherlands? Ecology and Society 21(4):43. http://dx.doi.org/10.5751/ES-08765-210443

van den Brink, M., C. Termeer, and S. Meijerink. 2011. Are Dutch water safety institutions prepared for climate change? Journal of Water and Climate Change 2(4):272-287. http://dx.doi. org/10.2166/wcc.2011.044

van Doorn-Hoekveld, W. J., S. B. Goytia, C. Suykens, S. Homewood, T. Thuillier, C. Manson, P. Chmielewski, P. Matczak, and H. F. M. W. van Rijswick. 2016. Distributional effects of flood risk management - a cross-country comparison of preflood compensation. Ecology and Society 21(4):26. http://dx.doi. org/10.5751/ES-08648-210426

Walker, B., C. S. Holling, S. R. Carpenter, and A. Kinzig. 2004. Resilience, adaptability and transformability in social-ecological systems. Ecology and Society 9(2):5. [online] URL: http://www. ecologyandsociety.org/vol9/iss2/art5/ 
Ward, P. J., B. Jongman, P. Salamon, A. Simpson, P. Bates, T. De Groeve, S. Muis, E. Coughlan de Perez, R. Rudari, M. A. Trigg, and H. C. Winsemius. 2015. Usefulness and limitations of global flood risk models. Nature Climate Change 5:712-715. http://dx. doi.org/10.1038/nclimate2742

Wardekker, J. A., A. De Jong, J. M. Knoop, and J. P. Van der Sluijs. 2010. Operationalising a resilience approach to adapting an urban delta to uncertain climate changes. Technological Forecasting and Social Change 77(6):987-998. http://dx.doi. org/10.1016/j.techfore.2009.11.005

Wesselink, A., J. Warner, A. Syed, F. Chan, D. Duc Tran, H. Huq, F. Huthoff, F. Le Thuy, N. Le Thuy, N. Pinter, M. Van Staveren, P. Wester, and A. Zegwaard. 2015. Trends in flood risk management in deltas around the world: are we going 'soft'? International Journal of Water Governance 3(4):25-46. 